\title{
ÁUDIO DINÂMICO: O DESIGN DE SOM NOS AMBIENTES INTERATIVOS
}

\section{DYNAMIC AUDIO: INTERACTIVE ENVIRONMENTS'SOUND DESIGN}

\author{
Luiz Roberto Carvalho ${ }^{1}$, M.Sc. \\ Alice T Cybis Pereira ${ }^{2}, \mathrm{PhD}$ \\ (1) Universidade Federal de Santa Catarina \\ e-mail: semprecarvalho@gmail.com \\ (2) Universidade Federal de Santa Catarina \\ e-mail: acybis@gmail.com
}

\begin{abstract}
Design de Interface, Design de Som, Áudio Dinâmico
Nos ambientes interativos, o uso do som não tem avançado como tecnologia na mesma proporção de desenvolvimento dos elementos gráficos, e a predominância do estímulo visual tem feito com que usuários - e desenvolvedores - tomem a ausência do estímulo sonoro como um padrão. Como resultado, tem-se experimentado um universo de interfaces nãosonoras ou poluídas acusticamente. No entanto, nos últimos 20 anos, uma série de esforços tem sido conduzidos por diversos pesquisadores para que o som adquira significado e relevância na área de IHC. O presente estudo objetiva sumarizar tais esforços, bem como expor os conceitos pertinentes do áudio dinâmico, e contextualizar sua aplicação. Ao levantar tais questões, busca-se contribuir para que as discussões acerca do design de som e do design de interface adquiram relevância, e a temática de estudo venha a se desenvolver de modo consistente.
\end{abstract}

\section{Interface Design, Sound Design, Dynamic Audio}

In interactive environments, the use of sound has not advanced as technology in the same proportion of graphics, and the predominance of visual stimulus has caused users - and developers - to take the absence of sound stimulus as a standard. As a result, a universe of non-audible or acoustically polluted interfaces has been tried out. However, in the last 20 years, a number of efforts have been conducted by several researchers to make the sound studies significative and relevant in the area of HCI. The present study aims to summarize such efforts, as well as expose the concepts of dynamic audio, and also contextualize its application. In raising such questions, the study seeks to contribute to related discussions about sound design and interface design.

\section{Design de Som}

Todos os sinais sonoros carregam dados, no entanto, nem todos os sons são capazes de transmitir informações. Isto é particularmente relevante quando sons são produzidos artificialmente, ou seja, quando produtos sonoros são criados com propósitos específicos - em oposição aos eventos acústicos circundantes, do ambiente. O design de som apropria-se dos sons de modo a transmitir mensagens sistematicamente. O sinal acústico é explorado, a fim de maximizar seus efeitos. $\mathrm{O}$ design de som lida com a perspectiva de construir sinais capazes de evocar reações afetivas e respostas cognitivas a partir de objetivos previamente estabelecidos.

Para Moses (2010), design de som (do inglês sound design) é o processo de planejamento, criação e tratamento de áudio de modo a destacar e enaltecer uma narrativa ${ }^{1}$. Murch (2005) cunhou o termo design de som depois de criar os sons para o filme Apocalypse Now (1979) que, juntamente com Star Wars (1977), modificaram substancialmente a abordagem da utilização de sons no cinema e, consequentemente, nas demais mídias audiovisuais.

Jekosch (2006) coloca que, sob o ponto de vista do design de som, condicionar as reações acerca dos eventos sonoros é um critério de projeto majoritário,

\footnotetext{
${ }^{1}$ Barthes (1976) afirma que o processo de leitura de uma narrativa não se restringe à simples passagem de palavras, mas refere-se á uma transposição de níveis de entendimentos e interpretações, onde, durante sua compreensão, são projetados encadeamentos em reconhecidos estágios. A narrativa pode ser sustentada pela linguagem articulada, oral ou escrita, pela imagem, fixa ou móvel, pelo gesto, pela mistura ordenada destes elementos, e por todos os demais processos comunicativos geradores de significado.
} 


\section{Ergodesign \& HCI}

sendo que a qualidade de um som pode ser considerada elevada se um evento acústico é percebido como portador de informação, e um significado específico seja extraído desse estímulo. Jekosch (2006) sugere que o ouvinte dispõe de um sistema de aquisição de sons e seus significados ou, em termos técnicos, de um conjunto léxico ${ }^{2}$ de sons. Este conjunto léxico contém recursos auditivos invariantes, como a forma do som (como o som típico causado por um martelo batendo em metal), seu conteúdo respectivo de experiência (som forte de colisão), e suas inter-relações de funções (utilizar a pancada do martelo para forjar o metal). Tais itens lexicais são constituintes de informação necessários para que o significado associativo do som seja extraído: quando há uma satisfatória correspondência entre dados de percepção, dados de experiência e expectativa, o evento sonoro adquire significado. Assim, ao ouvir-se determinado tipo de som, sistemas significação são ativados e consultados como referência, sendo o estímulo auditivo um tipo de sinal que atua conjuntamente com a memória. Quando um indivíduo é exposto a estímulos auditivos desconhecidos, as características desse sinal acústico são correlacionadas com um sistema interno de significados que contém tudo o que foi vivenciado pelo indivíduo, de modo que essas novas informações acústicas sejam apreendidas.

A problemática acerca do fato dos sinais sonoros serem potenciais portadores de informação está intimamente ligada à atenção, à experiência e as expectativas dos indivíduos. Liljedahl (2011) pontua que antes mesmo do nascimento a percepção auditiva dos humanos já é atuante. Após nascer, desde o primeiro dia de vida, o indivíduo começa a perceber e interpretar sons como resultados de eventos que ocorrem no mundo físico por meio de uma relação direta de causalidade, e inicia a construção de uma "biblioteca de associações de eventos sonoros". A este conjunto de eventos acústicos associam-se significados que permitem ao ouvinte classificá-los e interpretá-los. Por conseguinte, todos os sinais acústicos - naturais ou construídos - são percebidos como portadores de informações específicas. O rugido do interior de um

\footnotetext{
2 Léxico pode ser definido como o acervo de palavras de um determinado idioma: todo o universo de palavras que as pessoas de uma determinada língua têm à sua disposição para se expressar, oralmente ou por escrito
}

veículo, por exemplo, sugere esportividade, o barulho de um carro antigo sugere nostalgia, um grito estridente de uma criança sugere perigo, todos esses sinais significam algo para o ouvinte. Isso ocorre porque durante a audição memórias são despertadas e associadas ao evento auditivo, e o significado desse estímulo acústico atua de acordo com o repertório de experiências vivenciadas pelo indivíduo.

O som conecta o indivíduo ao mundo físico informando sobre a relação entre objetos e eventos físicos que o circundam. Nesse sentido, a consciência auditiva de um grupo de sons geralmente ocorre em virtude da audição de um elemento significativo que é parte integrante de um grupo de sons, como por exemplo, o som de cascos de um cavalo a galope não é idêntico à totalidade de sons que é emitida durante o galope, mas integra a composição sonora do galope. Nesse contexto, a percepção auditiva pode ser entendida como o ato de tornar-se consciente do todo em virtude das suas partes. Esse fenômeno é verdadeiro mesmo se o som é mediado através de um alto-falante: a percepção não diferencia os sons de um copo de vidro que vai ao chão e se quebra do som gravado do mesmo evento sendo disparado por um par de fones de ouvido com qualidade técnica compatível. De acordo com Liljedahl (2011), em indivíduos que já tiveram experiências em consultórios odontológicos com a utilização da broca, o som da mesma lhes confere uma sensação corporal quase que direta, e é possível praticamente senti-la na própria boca. No entanto, apenas a imagem da broca, sem o som característico, não surte o mesmo efeito sobre a imaginação, emoções e fisiologia humanas.

Possibilidades significativas de melhorias no campo do design de som são dadas quando o som é analisado sob uma ótica abrangente no que diz respeito às suas características de conteúdo, forma e função. A questão central, portanto, concentra-se em apontar como os ouvintes processam os eventos acústicos quando estes são tidos como processos de comunicação e, portanto, portadores de informações específicas. Susini et al (2006) afirmam que a estética do som e da música tem sido identificada como um valor de alta e baixa entropia (complexo; entediante). No design de som, questões estéticas podem ser reduzidas para problemas tratáveis, desde que a natureza do objeto seja explicitamente 


\section{Ergodesign \& HCI}

especificada. Em alguns casos, a função de um objeto é claramente definida (por exemplo, uma faca de cozinha é para o corte, logo, tem de ser afiada), e o contexto surge com a associação de sons já previamente apreendidos. Nesse contexto, propriedades que fornecem informações físicas, cinemáticas e processuais sobre a fonte sonora são relevantes para o design de som, pois através do som invariantes físicas podem ser apontadas, como tamanho, peso, material, e superfície. A cinemática, por exemplo, pode ser percebida ao explicitarem-se características como aceleração, desaceleração, parada brusca e impulso.

Susini et al (2006) apontam que durante os últimos 15 anos muitos projetos de pesquisa têm dirigido sua atenção para a medição da qualidade dos sons.

\section{Ruídos emitidos por objetos domésticos}

(interruptores de luz, aspiradores de pó, máquinas de café) e outros equipamentos (motores de automóveis, limpadores de para-brisa) já podem ser caracterizados e avaliados por métodos psicofisicos ${ }^{3}$, de acordo com escalas nominais bipolares (diferenciais semânticos) e por ferramentas de medição psicoacústica. No entanto, pesquisas em psicoacústica concentram-se principalmente nos ramos da fisiologia e neurologia da audição, e na determinação de atributos de percepção, como altura, intensidade, duração e timbre ${ }^{4}$ de determinado som. Há um enfoque na percepção dos atributos físicos do som em termos de tamanho e forma, e cria-se um espaço vazio no que diz respeito à sua correspondente emocional. Métodos psicoacústicos são capazes de caracterizar níveis de preferência e incômodo acústico em termos de resposta fisiológica do som, porém tais valores não consideram as respostas emocionais relacionadas aos aspectos funcionais e estéticos dos objetos sonoros.

A maioria dos sons percebidos no cotidiano possuem conotações emocionais que precedem sua

\footnotetext{
${ }^{3} \mathrm{Na}$ Psicofísica, três premissas são acordadas: o objeto de pesquisa da psicofísica é qualquer coisa que é sensorialmente percebida; por sua vez, qualquer coisa que existe no mundo é - em essência - algo que é percebido; a aparência de qualquer coisa percebida está inevitavelmente ligada a funções de organismos biológicos, em particular às funções cerebrais (BLAUERT, 2006).

${ }^{4}$ Conjunto de características que determinam um tipo específico de som: piano, violino, flauta. Eles podem tocar a mesma nota, mas serão bastante distintos, com ataques, decaimentos e conteúdo espectral diferente.
}

componente cognitiva e exercem influencia direta sobre a forma como são percebidos. Tractinsky et al (2000) afirmam que o sistema emocional modifica o nível de operação do sistema cognitivo, logo, as emoções permitem uma rápida tomada de decisão, enquanto a cognição ${ }^{5}$ permite interpretá-la e compreendê-la. Nesse sentido, uma abordagem sistemática acerca das reações afetivas dos usuários seria capaz de otimizar a predição de respostas relacionadas a produtos que possuem propriedades sonoras. Em termos de percepção, tais parâmetros sonoros são difíceis de estimar com alta precisão, tornando-se ainda mais complexos quando no domínio da hipermídia, que dão origem a uma equivalente perceptual que somente corresponde a uma realidade factual física aproximada, tendo em vista que muitos sons presentes nos dispositivos de IHC não possuem uma correspondente física, pois foram criados para a utilização no domínio da interface.

\section{A Problemática do Design de Som nos Ambientes Interativos}

Os ambientes interativos oferecem um campo novo e bastante singular de estudo que requer uma revisão de antigas teorias para que uma coerente abordagem entre design de som e design de interface possa ser realizada. Collins (2008) sugere cautela com o "imperialismo conceitual" quando da colonização dos estudos em interatividade por outras áreas. De fato, os ambientes interativos são muito distintos das formas tradicionais de mídia e, em muitos casos, a utilização de teorias advindas de outros campos pode não corresponder à completude de possibilidades e características que se aplicam no domínio da interface. Nesse contexto, as aplicações do som em plataformas interativas diferem-se das utilizadas nas mídias lineares tradicionais, como ocorre com a música, e o cinema. No domínio da IHC, a importância do som se concentra principalmente na sua capacidade de captar a atenção do usuário em distintos níveis cognitivos de modo a efetivar o processo comunicativo.

\footnotetext{
5 De acordo com Preece (2005), a cognição está relacionada ao que acontece em nossas mentes quando realizamos atividades cotidianas como pensar, lembrar, aprender, etc. Desmet \& Hekkert (2007) assinalam que através do processo cognitivo, como interpretação, recuperação de memória e associações, um indivíduo torna-se apto a reconhecer metáforas, atribuir personalidade ou outras características expressivas a um objeto, e acessar o significado pessoal ou simbólico dos produtos.
} 


\section{Ergodesign \& HCI}

A importância do som na interação com objetos virtuais já é bem conhecida. Corbett et al (2007) conduziu um estudo que assinala a evolução dos estudos acerca da utilização de sons em sistemas interativos apontando para a seguinte sucessão de fatos: Gaver (1986, 1989, 1992, 1993, 1993b) foi pioneiro no estudo do uso de sons sintéticos na interação humano-computador; Takala \& Hahn (1992) foram os primeiros a desenvolver uma proposta para a produção de efeitos sonoros em sincronia com animação, em que sons estão ligados a objetos e eventos gráficos; Hahn et al (1995) introduziu uma série de algoritmos para a criação de sons sintetizados em computador; porém, a técnica pioneira de produção de sons sintetizados foi desenvolvida por Cook (1995, 1996), amplamente utilizada na criação de efeitos sonoros para utilização em ambientes interativos.

No entanto, no ano de 1996, Stuart (1996) apontava que a utilização dos recursos tecnológicos em hipermídia se restringia somente a modalidade visual. De acordo com o autor, pouco se investiu em áudio $^{6}$, um elemento que traz qualidade para o conteúdo, facilita a acessibilidade das informações e as torna mais atraentes, além de seu baixo custo de produção, distribuição e uso. Dez anos após, segundo os estudos de Susini et al (2006), não houve avanços significativos em relação ao som. $\mathrm{O}$ autor aponta que no mercado de design existe uma supervalorização da comunicação visual, e devido as suas limitações, os produtos e serviços em design podem muitas vezes apresentar inconsistências quando demais propriedades sensoriais se fazem relevantes, como no caso de informações sonoras e táteis. No entanto, dispositivos portáteis como o tablet e o smarphone demonstram que o processo tátil e os requisitos hápticos ${ }^{7}$ avançam como

\footnotetext{
${ }^{6} \mathrm{O}$ termo áudio vem do latim audio, primeira pessoa do presente do verbo audire, que significa ouvir. Num sentido mais amplo, refere-se a todos os fenômenos de onda que ocorrem dentro do espectro das frequências audíveis, ou seja, entre $20 \mathrm{~Hz}$ e $20 \mathrm{kHz}$. Trata-se de uma área científica com intersecções na eletrônica, na acústica e na música, que estuda as aplicações que se destinam à geração, processamento, armazenamento, registro, manipulação e reprodução de informações sonoras sob distintas formas (elétrica, óptica, digital). Quando no domínio acústico, uma onda de áudio gera ondas sonoras e é conhecido como "som".

${ }^{7} \mathrm{O}$ adjetivo háptico significa "relativo ao tato", "sinônimo de tátil", e é proveniente do grego haptikós,ê,ón "próprio para tocar, sensível ao tato". É o correlato tátil da óptica (para o visual) e da acústica (para o auditivo). Fonte: Dicionário Houaiss da Língua Portuguesa. Objetiva, 2001 .
}

tecnologia, enquanto o som e suas funcionalidades cognitivas ainda permanecem pouco explorados no campo da Interação Humano-Computador.

Brewster (1994), um dos pioneiros nos estudos de som na IHC, pontua que quase todas as informações apresentadas por sistemas digitais utilizam-se apenas do canal visual, que implica na possibilidade de perda de informação em decorrência de limitações advindas da sobrecarga visual ou porque o usuário ${ }^{8}$ pode não dirigir os olhos para determinada informação relevante. $\mathrm{O}$ autor sugere que uma interface multimodal deve integrar a utilização de informações não somente advindas do canal visual, mas também utilizar-se do canal auditivo para apresentar as informações da forma mais eficiente possível. Quase duas décadas após os primeiros apontamentos de Brewster, a componente sonora da interface ainda permanece num estado de desenvolvimento incipiente. Parker e Heerema (2008) afirmam que o uso do som em ambientes interativos não tem avançado como tecnologia na mesma proporção de desenvolvimento dos elementos gráficos e, consequentemente, sua utilização em aplicações interativas tem sido muito mais reativa ${ }^{9}$ do que interativa. Em consonância, Liljedahl (2011) pontua que o desenvolvimento de interfaces web tem tradicionalmente colocado ênfase nos elementos gráficos, e a predominância do estímulo visual tem feito com que os usuários - e desenvolvedores - tomem a ausência do estímulo sonoro como um padrão. Estas circunstâncias têm contribuído para que os usuários tenham se acostumado com a desimportância factual do som, de modo a desenvolver associações negativas em relação às experiências auditivas presentes nas interfaces.

Nos últimos 15 anos, a apropriação da linguagem sonora pela hipermídia não apresentou avanços significativos. No ano de 2001, Bishop e Cates (2001) pontuaram que livros sobre design de interface raramente discutem o uso do som, e quando o fazem, o uso mais frequentemente discutido é o da simples narração de texto na tela. Em 2007, Follet (2007) pontuou que a escolaridade e formação profissional em design de interface e $U X$

\footnotetext{
${ }^{8}$ Usuário: pessoa que interage com o produto (ISO 9241, 2011).

${ }^{9}$ Sem a participação ativa do usuário.
} 


\section{Ergodesign \& HCI}

design ${ }^{10}$ é essencialmente baseada na área de design visual, ainda mantendo relações com a mídia impressa, não havendo nenhuma base de conteúdos em design de som. Em 2014, Collins e Kapralos (2014) apontaram que muitos docentes que ensinam design de interface não possuem instrução para lecionar assuntos relacionados ao som em suas disciplinas. De acordo com os autores, há recursos limitados para que os docentes se sintam aptos em instruir os alunos acerca do som. Por tal razão, alunos de design de interface muitas vezes completam seus graus acadêmicos sem seguir uma única classe relacionada ao som e a interatividade. Enquanto a integração de texto e gráficos é uma ocorrência familiar e comum no campo do design de interface, a utilização do som é território ainda desconhecido e raramente considerado, e como consequência, a aplicação do som nos dispositivos de IHC, tanto nos ambientes web e desktop quanto nos portáteis tablet e smatphone, ainda é caracterizada como uma prática incipiente, e subutilizada.

Roccheso et al (2008) indicam que esta ênfase exagerada em displays visuais tem limitado o desenvolvimento de sistemas interativos que são capazes de fazer um uso mais adequado da modalidade auditiva. $\mathrm{O}$ autor assevera que apesar de promissor e com já reconhecida importância, o design de som de interface não é uma disciplina estabelecida como ocorre com o design de interface gráfica. Por conseguinte, o uso do som em aplicações interativas tem sido colocado em segundo plano, e sons não musicais têm sido aceitos como subprodutos de tecnologias, ao invés de serem explorados por seu valor intrínseco. Como resultado, tem-se experimentado um universo de interfaces não-sonoras ou poluídas acusticamente.

De acordo com Alves e Roque (2011), o design de som de hipermídia permanece o ofício de uma minoria, e a ausência de um organismo de conhecimento sobre o assunto tem contribuído grandemente para a manutenção desse estado de coisas. Um sinal evidente da falta de um corpo relevante de conhecimentos é a indisponibilidade de diretrizes ${ }^{11}$ claras ou boas práticas sobre design de

\footnotetext{
${ }^{10}$ Do inglês user experience design; design para a experiência do usuário, em tradução livre.

${ }^{11}$ O Novo Dicionário Eletrônico Aurélio (2016) define "diretriz" como um conjunto de instruções ou indicações para se levar a termo um plano,
}

som de interface. No entanto, no que diz respeito à modalidade visual da hipermídia, este tipo de apoio existe e já é amplamente conhecido e difundido. Nesse contexto, os autores apontam dois aspectos relevantes para que uma reorientação da investigação do som na interface possa ocorrer: a sensibilização e o suporte. Isto significa fazer com que acadêmicos e profissionais da área de design de interface tornem-se mais conscientes da baixa apreciação que a componente sonora possui, e desse modo venham a combater essa tendência através da proposição de formas inovadoras para explorar o seu potencial.

No entanto, para Collins (2013), muitas vezes uma peça essencial para que a abordagem sobre som e interface possa ser concretizada é negligenciada: o usuário. Embora seja relativamente simples especificar distintas estruturas interativas na interface, é complexo lidar com as experiências resultantes da interação entre a plataforma e o usuário. Nesse contexto, a interação com o som é fundamentalmente diferente da sua simples audição. Em seu nível mais básico, a interação altera as formas com que os indivíduos se relacionam com os sons, pois cria uma relação experiencial distinta da mera audição: interagir com o som é fundamentalmente diferente de apenas ouvi-lo. A questão central, portanto, concentra-se em apontar como os usuários de hipermídias processam os eventos acústicos, ou seja, como os estímulos sonoros são capazes de transmitir informações específicas. Nesse sentido, Cancellaro (2006) pontua que a grande questão que envolve a utilização de sons nos sistemas interativos não se encontra mais no desafio técnico de aplicar estes sons na plataforma de programação do aplicativo, pois as barreiras tecnológicas e de custo para a plena integração do som nas interfaces já desapareceram, e conclui que o foco deve direcionar-se ao som como transmissor de uma mensagem pretendida.

\subsection{O Som nas Aplicações Interativas}

Em aplicações interativas, sinais auditivos podem auxiliar o usuário a se orientar, aumentar sua sensação de presença, aumentar o desempenho de

uma ação, um negócio, diretiva. O Cambridge International Dictionary of English (2016, em tradução livre) define "diretriz" como uma informação com a intenção de orientar pessoas sobre o que deve ser feito e como deve ser feito. 


\section{Ergodesign \& HCI}

tarefas e adicionar imersão. Collins e Kapralos (2014) apontam que o som é capaz de comunicar informações importantes ao usuário, como situá-lo num local específico no tempo e no espaço, e criar um senso de "realismo" no ambiente virtual. Em particular, o som desempenha uma importante função de imergir o usuário e estimular seu envolvimento emocional com a interface. De acordo com Brewster (1994), um dos pioneiros no estudo do som na IHC, há muitas razões pelas quais é importante utilizar sons em interfaces, a saber:

a) Quando a informação é representada de forma visual, os usuários devem centrar sua atenção no dispositivo de saída (monitor de vídeo), a fim de obter as informações. Sons, por outro lado, possuem uma natureza omnidirecional, e podem ser ouvidos sem a necessidade do usuário concentrar-se num dispositivo de saída, proporcionando assim maior flexibilidade;

b) O som chama a atenção. Os usuários podem optar por não olhar para a tela, mas não podem evitar ouvir sons. Isso faz com que o sistema auditivo seja uma via ideal para a apresentação de alarmes e advertências;

c) Há evidências que sugerem que a partilha de informação entre distintas modalidades sensoriais pode melhorar o desempenho de execução de uma tarefa. Correlações intermodais resultantes da partilha entre os sentidos visual e sonoro podem tornar a interface mais natural. O som clássico de "papel sendo amassado" quando um arquivo é colocado na lixeira do computador é um exemplo;

d) Alguns objetos ou ações dentro de uma interface podem adquirir uma representação mais natural se expressos através do canal auditivo. Sons são úteis para fornecer informações sobre processos em segundo plano e acerca do funcionamento interno de um sistema, sem comprometer a atenção visual das tarefas em foco.

Tong \& Wong (2006) afirmam que ambientes interativos que não utilizam som possuem um impacto significativamente reduzido. O som é capaz de reduzir a carga no sistema visual do usuário, bem como tornar as interfaces utilizáveis por usuários com deficiência visual. Nesse contexto, usuários com problemas de visão podem ficar tão sobrecarregados de informações visuais que efetivamente tornam-se "deficientes visuais" diante da interface, pois o canal visual sobrecarregado reduz consideravelmente a capacidade de absorção e assimilação de informação através dos olhos.

Este é o caso da de interfaces eyes-free, nas quais o usuário deve manter contato visual com outros elementos do ambiente ou onde a visão é comprometida por outros conjuntos de ação, como por exemplo, ao utilizar o GPS num enquanto dirige um veículo. Nesse sentido, existem formas de intensificar a experiência de áudio quando os usuários não estão olhando ou não podem interagir com a componente visual da interface, e há uma série de considerações a pontuar quando da utilização do som nestes dispositivos. Quando não é possível - nem desejável - dirigir os olhos para o display visual da interface, o áudio se torna indispensável. Por exemplo, ao utilizar um smartphone no transporte coletivo (trem, metrô, ônibus), é muito comum que os usuários ouçam música, naveguem na internet, joguem games, sendo esta uma abordagem consideravelmente distinta da utilização de um GPS, onde o som desempenha um papel extremamente relevante no fornecimento de informações ao usuário. Ao utilizar um GPS é possível determinar se o usuário está parado, analisando os mapas visualmente, ou em movimento, e dessa forma o sistema é capaz de identificar se sua visão está ocupada. Nesse sentido, o status do dispositivo é um relevante indicativo do tipo de engajamento que o usuário possui com a interface, e denota variantes importantes acerca dos canais sensoriais mais apropriados para a interação.

Por outro lado, smartphones e tablets são projetados com o conhecimento de que tais dispositivos são utilizados frequentemente na presença de outras pessoas, o que pode exigir silêncio, como aponta a empresa de aparelhos de telefonia Nokia (NOKIA Corp, 2005), que alerta que estes devem ser utilizados com e sem a utilização de sons. No entanto, Kaushansky (2012) pontua que uma boa experiência inclui feedback ${ }^{12}$ de ação para cada input

\footnotetext{
${ }^{12}$ Norman (2006) pontua que o feedback é um conceito muito utilizado na ciência de teoria e controle de informações. Trata-se de fornecer ao
} 


\section{Ergodesign \& HCI}

do usuário, como por exemplo, ao pressionar uma tecla numérica sobre um smartphone, um som de confirmação de ação é disparado enquanto o número é exibido para visualização. Mears (2014) relata que em observações de testes de usabilidade os indivíduos de idade mais avançada ou os menos confortáveis com a tecnologia em muitos casos possuem o som de feedback do toque tap (toque dos dedos na superfície tátil) das teclas ativado em seus smartphones. $\mathrm{O}$ autor aponta que normalmente a primeira atividade que muitos usuários jovens fazem é desligar este tipo de retorno sonoro, uma vez que pode ser considerado irritante em ambiente público. No entanto, para os usuários que estão acostumados com teclados de interfaces desktop clássicas (que emitem sons físicos ao digitar) e não estão familiarizados com a tecnologia touch screen, esse feedback de áudio proporciona uma confirmação de ação, sendo que sem o mesmo a percepção de envio e recebimento de dados com a interface se faz incipiente.

No caso de interfaces já munidas de sons, Iuppa \& Borst (2010) apontam que desativar o áudio em algumas situações pode restringir substancialmente as possibilidades de imersão e interatividade, fenômeno comumente observado nos títulos de games. Collins (2008) pontua que desligar o áudio colocará o usuário em situações de maior dificuldade, tendo em vista a ausência do feedback auditivo, que é muito utilizado como indicativo de eventos que estão ocorrendo, mas não são visualizados. No título do game New Super Mario Bros para o console Nintendo DS (Nintendo, 2004), por exemplo, os adversários saltam e voam de acordo com o tempo da música. Logo, ouvir os sinais sonoros pode indicar ao usuário o momento exato de executar determinados movimentos para o sucesso da tarefa. Nesse contexto, se não houver um nível básico de sons na trilha sonora do aplicativo, uma atmosfera insuficiente será percebida pelo usuário e a experiência de imersão será comprometida pela insuficiência de estímulos sonoros.

O grau variável com o qual o usuário pode interagir com o som sugere que o áudio em ambientes interativos pode servir a uma grande variedade de

usuário o retorno, a realimentação de informações sobre a ação que foi executada. funções, no entanto, é importante pontuar que a interface gráfica ${ }^{13}$ irá influenciar na percepção dos estímulos auditivos, logo, ambos devem atuar de modo congruente, e ser projetados em complementaridade.

\subsection{Audio Dinâmico: Interativo Direto e Adaptativo Indireto}

Em discussões sobre áudio em ambientes interativos, Collins (2008) aponta que o termo interativo é por vezes utilizado para intercambiar ou ampliar o significado de termos como reativo e adaptativo. $\mathrm{O}$ áudio interativo se refere aos eventos sonoros resultantes da interação direta do usuário, já o áudio adaptativo é um tipo de som que reage ao estado da interface, respondendo de maneira automatizada a distintos parâmetros, como localização espacial, condição narrativa, estados de alerta, entre outros. Para evitar que os termos possam gerar ambiguidade, a autora sugere a utilização do termo áudio dinâmico para definir os eventos sonoros ocorridos na interface, sejam estes de natureza interativa ou adaptativa. É o áudio que reage tanto às mudanças no ambiente quanto à resposta do usuário.

Para Collins (2008), o áudio interativo é definido como qualquer evento sonoro que reage a um sinal de entrada direto do usuário, levando a uma reação de causalidade simples, ou seja, com correspondência isomórfica, ponto-a-ponto, como por exemplo, o som emitido ao pressionar-se um botão no teclado para efetuar determinada ação. Já o áudio adaptativo, por outro lado, é o som que reage aos estados da interface, respondendo a vários parâmetros pré-estabelecidos, como contagem de tempo, performance, entre outros. O disparo de um som sob a mecânica do áudio adaptativo não é plenamente determinado pela ação direta do usuário, ou seja, o resultado sonoro envolve outras variáveis do próprio sistema, sobre as quais o usuário não possui controle direto. Um exemplo de áudio adaptativo encontra-se no game Super Mario Bros (Nintendo Inc., 1993), no qual o ritmo da música

\footnotetext{
${ }^{13}$ Em computação, uma Interface Gráfica de Usuário (do inglês GUI, Graphical User Interface) é um tipo de interface que permite aos usuários interagir com dispositivos eletrônicos com imagens, ao invés de comandos de texto. A GUI representa as informações e ações disponíveis para o usuário através de ícones gráficos e indicadores visuais, em que as ações geralmente são realizadas através da manipulação direta dos elementos gráficos.
} 


\section{Ergodesign \& HCI}

aumenta quando o cronômetro do jogo atinge poucos segundos para a conclusão do nível, como forma de alertá-lo que o tempo irá se esgotar em breve. $\mathrm{O}$ áudio interativo refere-se aos eventos sonoros disparados diretamente pelo usuário, como por exemplo, quando um botão é pressionado, ou quando o cursor do mouse passa sobre um item que emite um som. Já o áudio adaptativo diz respeito aos estímulos sonoros resultantes da participação indireta do usuário nos ambientes interativos. De acordo com Bar-B-Q (2003), os estímulos sonoros presentes nos sistemas interativos podem ser classificados como áudio interativo direto e áudio interativo indireto. No entanto, Collins (2008) aponta que o grupo de sons pertencente ao domínio da interface pode ser classificado como áudio dinâmico, e os divide em áudio interativo e áudio adaptativo. Como tais conceitos são concordantes entre si, e objetivando minimizar a possibilidade de ambiguidade das nomenclaturas, assume-se a categorização dos termos áudio interativo direto $\mathrm{e}$ áudio adaptativo indireto, ambos pertencentes ao grupo do áudio dinâmico, como proposto na figura a seguir:

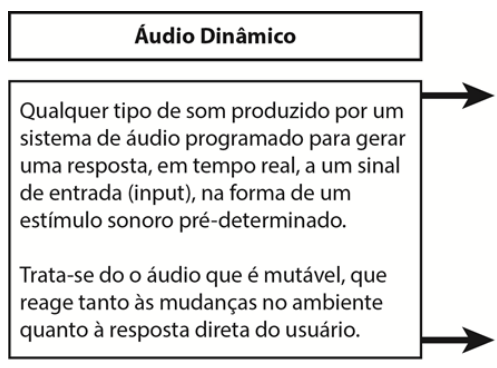

\begin{tabular}{|l|}
\hline \multicolumn{1}{|c|}{ Áudio Reativo } \\
\hline $\begin{array}{l}\text { Um sistema reativo simplesmente } \\
\text { reproduz estaticamente eventos de } \\
\text { áudio sem qualquer adaptação em } \\
\text { relação ao estímulo do usuário. }\end{array}$ \\
\hline
\end{tabular}

Figura 1: Proposição terminológica: áudio dinâmico, interativo direto, adaptativo indireto e reativo.

Segundo Bar-B-Q (2008) dentre as principais características do áudio interativo, podem-se destacar as seguintes:

a) Melhora na experiência do usuário através do aumento dos níveis de imersão;

b) Criação de uma experiência participativa;

c) Possibilita a realização de novos tipos de atividades;

d) É potencialmente mais barato de implementar.
Dentre as possíveis plataformas de aplicação do áudio interativo destacam-se os ambientes virtuais, games, websites, players de música, e-books, softwares, smartphones, automóveis, eletrodomésticos, brinquedos. Devido à sua natureza, conforme os dispositivos digitais se desenvolvem, maiores tornam-se as possibilidades de aplicação do áudio interativo.

Leonard Paul, compositor e sound designer de games, apresenta um sistema que ilustra a utilização dos princípios do áudio dinâmico:

"O jogador está em um pântano, a paisagem sonora é composta de sons de sapos, moscas, pássaros e vento; cada um desses elementos está em um plano sonoro diferente - os sapos e o vento ao fundo, as moscas e os pássaros mais próximos; eles interagem entre si-quando o vento aumenta, as moscas diminuem. De repente, o jogador dá um tiro. O tiro irrompe a paisagem e a cala: só se ouve o vento. Os viventes, calados, aos poucos vão se reconstituindo: primeiro os sapos, depois as moscas, muito depois os pássaros" (MENEGUETTE, 2011, p.5).

Senero não é determinado apenas pelo input do

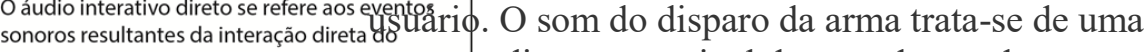
usuário. No caso direto, o usuário contrpesposta direta a um sinal de entrada, sendo audio conscientemente. classifflcado como áudio interativo direto. No Áudio Adaptativo Indireto entanta as reações sonoras do ambiente, É um tipo de som que reage ao estado Ǵdhdio adaptativo indireto, pois podem variar, neste face, ao seu status, respodendo automationntex to, conforme a localizaçãa espacial do o usuário está controlando algum outrdisuárí, $\phi$, e não há controle direto sobre o início ou o parâmetro, que por sua vez, afeta o compgerțninino das resultantes sonoras.
mento do áudio na interface.

\subsection{Funções do Áudio Dinâmico}

O Interactive Audio Special Interest Group (IASIG, 2012; Grupo de Interesse Especial em Áudio Interativo, em tradução livre) propõe uma série de funções do áudio dinâmico, afirmando a existência de uma considerável sobreposição entre estas categorias, e reiterando que as mesmas não devem ser consideradas mutuamente excludentes. Estas funções dividem-se em semióticas, emocionais (intimamente ligadas à função semiótica), estruturais, narrativas, imersivas, estéticas e cinéticas. 


\section{Ergodesign \& HCI}

De acordo com o IASIG (2012), as funções semióticas do áudio dinâmico buscam transmitir um significado emocional, preparatório, visando concentrar a atenção do usuário para identificar objetivos, de tal modo que seja possível diminuir a curva de aprendizagem, adicionando um grau de inclinação positiva na interação com a interface. Símbolos de som ajudam a identificar objetivos e focalizam a percepção do usuário em determinados objetos. Em muitos games, por exemplo, a presença de inimigos dispara uma música tensa, já quando se encontram elementos benéficos, como moedas, pontos de vida em forma de coração, estes acabam apresentando sugestões sonoras suaves, comumente interpretadas como positivas. Em outras palavras, símbolos sonoros são muitas vezes utilizados para auxiliar o usuário na identificação de outros elementos da interface, podendo induzir a sugestão de humor e sentimento, sejam estes incorporados nos ambientes ou nos próprios objetos interativos, de tal forma que seja possível tornar a interface mais compreensível e de rápida assimilação.

Um papel semiótico crucial que o som dinâmico exerce diz respeito à sua função preparatória $\mathrm{e}$ antecipatória, por exemplo, para informar o usuário em relação a um estado de interface. Em games, antecipar a ação é um elemento crítico, principalmente em títulos de aventura. Sons nãodiegéticos, ou seja, sem clara indicação visual, podem incentivar o usuário a olhar para a direção de um som. Tão importante quanto os elementos preparatórios do áudio dinâmico é o uso do som para adicionar uma tendência comportamental e cognitiva, mudando a perspectiva do usuário em relação à interface.

As funções emocionais estão intimamente relacionadas com as semióticas. Aqui, uma distinção deve ser feita entre a comunicação de significado através da música, e a indução de estados de humor: o humor muda de acordo como o usuário está se sentindo, enquanto os aspectos emocionais semióticos simplesmente transmitem informações. $\mathrm{O}$ usuário pode compreender que um som remete tristeza, sem necessariamente estar se sentindo triste. Uma quantidade considerável de sons nas interfaces possui efeitos emocionais, que podem aumentar ou diminuir o grau de dificuldade para a execução de uma tarefa, como no caso do aumento de ritmo de uma composição conforme uma tarefa é executada. Desta forma, o som funciona para controlar ou manipular as emoções do usuário, orientando as respostas para o que a interface pretende.

As funções estruturais do áudio dinâmico estão ligadas ao ato de criar, reforçar ou mascarar a estrutura da interface, através das quais se torna possível indicar mudanças na narrativa e situar o usuário. Como nos filmes, música e sons são utilizados frequentemente em interfaces para reforçar ou melhorar sua estrutura de continuidade. Um exemplo significativo da utilização das funções estruturais de áudio dinâmico encontra-se no game Vib Ribbon (SCEI, 1999), no qual a música pode literalmente direcionar a narrativa de conteúdo. Lançado no Japão para o console Playstation, o jogo permite ao usuário inserir seu próprio disco de música, que será então utilizado como referência para um mapeamento dos níveis de dificuldade. Através das características do áudio, o jogo executa dois cursos de obstáculo para cada música (um fácil e um difícil), ou seja, a estrutura narrativa da interface pode variar de acordo com a música escolhida. Embora este seja um caso bastante singular, a utilização de músicas e faixas de áudio para a criação de estruturas de interface é um recurso que possui significativo potencial. No entanto, o áudio dinâmico é utilizado com mais frequência para melhorar a estrutura geral da interface. A inclusão de pistas sonoras intermediando dois estados de interface atua como elemento de ligação para uma transição gradual e contínua nos conteúdos. Um breve silêncio pode informar ao usuário que o tempo para a execução de uma tarefa possa ter sido encerrado, ou que algo está por ocorrer, sendo indicativo de possíveis mudanças no estado de interface.

Em muitos casos, sinais de áudio podem ajudar a situar o usuário no contexto narrativo da interface. Ao ouvir distintas composições musicais em locais diferenciados, o usuário é capaz de identificar seu paradeiro através desta resposta de sons. O áudio é muitas vezes usado para localizar o usuário no enredo, ancorando-o em termos de onde, quando e $o$ que está acontecendo, bem como servindo como elemento de antecipação do que está por vir. O diálogo pode também servir como um grande evento na narrativa, sendo utilizado na revelação de informações e para a atribuição de metas e tarefas 


\section{Ergodesign \& HEI}

específicas da aplicação. Sons não-verbais podem também revelar detalhes sobre ambientes e objetos através de criação de climas de ambiência (do inglês ambient moods), particularmente úteis para criar empatia e familiarização, tornando as interfaces mais imersivas.

A função imersiva desempenha um papel crítico no áudio dinâmico, pois lida diretamente com a "suspensão de descrença da interface", adicionando realismo através da criação de uma "ilusão do real", indispensável para a imersão do usuário. O IASIG (2012) aponta que a ilusão de estar imerso em um ambiente tridimensional é bastante reforçada pelo áudio. Além de integrar o usuário na narrativa da interface, o áudio dinâmico pode também ser utilizado para fazer com que os sons da aplicação direcionem o foco do usuário de tal modo que este não se distraia com os estímulos sonoros produzidos pelo ambiente circundante, sejam estes ruídos, vozes, sons diversos. O áudio dinâmico pode funcionar, então, para ajudar a abafar ou mascarar os sons externos, na medida em que aumenta progressivamente a concentração e o foco na tarefa da interface.

As funções estéticas do áudio dinâmico lidam com a criação de identidades e referências intertextuais da interface, onde o som é usado para criar beleza, Funçöes Semióticas gerando aceitação e familiaridade. A função esté oferece a possibilidade de criação de climas, quє fornecem pistas sobre as características da interf

Músicas introdutórias lentas e suaves, por exem Funçöes Emocionais geralmente indicam que a interface possui um rit de tarefa leve. Composições musicais mais aceleradas geralmente são indicativas de ação e dinâmica. Certos gêneros de música se adaptam a certos tipos de interfaces, tendo em vista que distintos tipos de narrativas possuem diferentes requisitos de interatividade.

As funções cinéticas conectam um estímulo sensorial de áudio a uma resposta motora especí dos indivíduos. Algumas interfaces são projetad: para que os usuários possam interagir diretamen com estímulos sonoros e movimentos físicos, como o game de dança Dance Dance Revolution (Konami, 2000), e o título EyeToy Kinetic (Sony, 2005) que propõe um certo grau de treinamento de habilidades motoras básicas, contribuindo para $\mathrm{o}$ condicionamento físico do usuário. $\mathrm{O}$ áudio

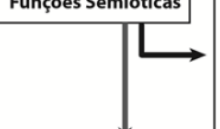

Funçōes Estruturais
Funçōes Narrativas dinâmico cinético serve como principal fator motivador para a execução dos movimentos, pois é o elemento primário que confirma (ou rejeita) a execução correta de uma tarefa no contexto da interface.

No que concerne às funções cinéticas do áudio dinâmico, atualmente tem-se observado que a aparência sônica dos objetos é algo que está cada vez mais se tornando maleável e dinamicamente modificável, como no caso de microprocessadores e alto-falantes incorporados nos objetos. Exemplos deste tipo já estão no mercado, como o controle do console de game Nintendo Wii (Nintendo), que incorpora sensores giroscópicos de aceleração juntamente com um alto-falante embutido. Desta forma, percepção e ação estão fortemente acopladas via manipulação direta, com a adição de um feedback acústico localizado onde está a ação do movimento físico. Susini et al (2006) pontua como exemplo uma experiência de jogo de tênis virtual, que se torna muito mais envolvente com este tipo de controlador.

A figura a seguir sintetiza as principais características apontadas pelo IASIG (2012) como fundamentais para que o áudio possua um papel relevante no contexto de interfaces interativas:

As funçōes semióticas do áudio dinâmico buscam transmitir um significado As funçoes semioticas do audio dinàmico buscam transmitir um significado hocional, preparatono, visando concentrar a atença do usuanio para identifar an juda gidentificar ajje objetos da interface.

As funçōes emocionais estão intimamente relacionadas com as semióticas. Uma quantidade considerável de sons nas interfaces possui efeitos emocionais, que podem aumentar ou diminuir o grau de dificuldade para a execuçăo de uma tarefa, como no caso do aumento de ritmo de uma composição conforme uma tarefa é executada. Desta forma, o som funciona para controlar ou manipular as emoçōes do usuário, orientando as respostas para o que a interface pretende.

Funçōes estruturais estão ligadas ao ato de criar, reforçar ou mascarar a estrutura da interface, através das quais se torna possivel indicar mudanças na narrativa e situar o usuário. Como nos filmes, música e sons são utilizados frequentemente em interfaces para reforçar ou melhorar sua estrutura de continuidade, pois a inclusão de pistas sonoras intermediando dois estados de interface atua como elemento de ligaçăo para uma transiçăo gradual e contínua nos conteúdos.

Em muitos casos, sinais de áudio podem ajudar a situar o usuário no contexto narrativo da interface. Ao ouvir distintas composiçōes musicais em locais diferenciados, o usuário é capaz de identificar seu paradeiro no enredo, ancorando-o em termos de onde, quando e o que está acontecendo. $O$ diálogo pode também servir como um grande evento na narrativa, sendo utilizado na revelação de informaçōes e para a atribuição de metas e tarefas especificas da aplicação. Sons não-verbais podem também revelar detalhes sobre ambientes e objetos através de criaçăo de climas de ambiência (ambient moods), particularmente úteis para criar empatia e familiarização, tornando as interfaces mais imersivas. 


\section{Ergodesign \& HCI}

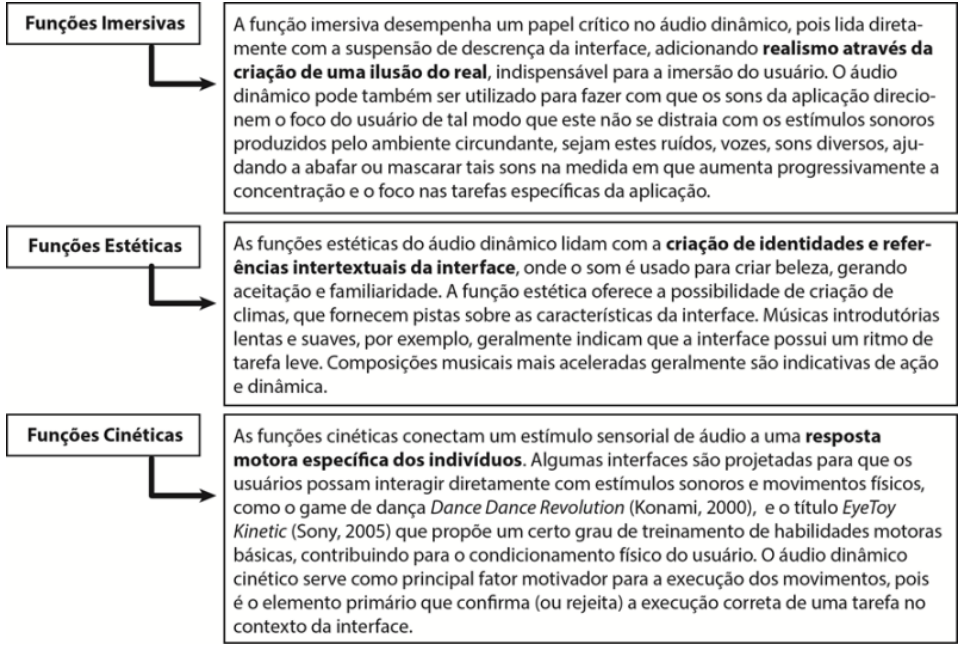

Figura 2: Funções do Áudio Dinâmico. Fonte: CARVALHO, GONÇALVES \& PEREIRA, 2012, p. 4.

\subsection{Imersão e Áudio Dinâmico}

Ao vivenciar uma narrativa num ambiente interativo, Murray (2003) aponta para a existência de três princípios estéticos:

a) A imersão, que é a capacidade do usuário se sentir presente em outro lugar, vivenciando tudo que o mesmo proporciona;

b) A agência, que é a sensação que o usuário tem ao obter um resultado relevante e imediato quando se realiza uma determinada ação;

c) A transformação, que é a possibilidade permitida nos meios digitais em mudar formas e conteúdos dos seus elementos.

De acordo com Jennett et al. (2008) a imersão é uma experiência que inclui a supressão de todos os ambientes (espacial e temporal), com a sensação de estar em outro ambiente. Isto sugere que a imersão é uma experiência relacionada com o processamento cognitivo e a atenção: quanto mais imersiva é uma experiência, mais atenção é exigida do usuário. A imersão seria provocada como resultado de uma ação que pede uma resposta emocional que influencia a atenção e, consequentemente, leva a imersão. A imersão pode ser descrita como uma sensação crescente, uma experiência que se desenrola ao longo do tempo e é dependente da prontidão perceptiva dos usuários.

Salen \& Zimmerman (2003) denominam de falácia imersiva a ideia de que o prazer de uma experiência de mídia reside em sua capacidade de transportar o participante para uma simulada realidade, tão completa que, idealmente, a interface desaparece e o usuário realmente acredita que faz parte da mesma. Grau (2003) aponta que imersão caracteriza-se por diminuir a distância crítica entre o que é exibido e o usuário, e desse modo amplificar seu envolvimento emocional. Nesse contexto, Jørgensen (2006) aponta que o grau de realismo fornecido por sinais sonoros é um facilitador primordial para a imersão.

Um espaço de imersão realista é desenvolvido com um grau de naturalidade mediado por distintos entendimentos de percepção. No caso de interfaces projetadas para games, estes raramente são situados em mundos realistas, e mesmo quando o são, não se trata de uma simulação da realidade, mas um realismo cinematográfico que se baseia em convenções já estabelecidas, como ocorre com o cinema, com seus exageros que extrapolam as próprias leis físicas. Ermi \& Mäyrä (2005) dividem a imersão em três níveis. A primeira dimensão é a da imersão sensorial, onde grandes aparatos de visualização de imagem perto do rosto do jogador e poderosos sistemas de som facilmente dominam as informações sensoriais vindas do mundo real, e o jogador fica totalmente focado no universo do game e nos seus estímulos. A segunda forma é baseada em desafios de interação, onde se deve haver um equilíbrio satisfatório entre desafios requeridos e habilidades necessárias. O terceiro nível de imersão é imaginativo, que tem significado quando o game oferece ao jogador a chance de usar sua imaginação, criar empatia com personagens, ou simplesmente desfrutar da fantasia do jogo. Particularmente, a dimensão imersiva imaginativa é fortemente reforçada pela utilização do som.

O áudio desempenha um papel significativo na qualidade imersiva de uma interface. Qualquer tipo de interrupção na interação distrai o usuário e reduz seu grau de imersão. Em relação ao áudio, isso se dá quando há interrupções na trilha sonora da interface, como no caso de transições abruptas entre pistas sonoras sem a utilização de $f a d e^{14}$, e com a prática exaustiva de looping ${ }^{15}$. Collins (2008) pontua que nos games o áudio dinâmico se constitui requisito

\footnotetext{
${ }^{14}$ Termo técnico utilizado para indicar a diminuição gradual de um som até que o mesmo torne-se inaudível.

15 Trechos de áudio (como uma batida ou riff de guitarra) que podem ser concatenados e repetidos consecutivamente.
} 


\section{Ergodesign \& HCI}

indispensável para o sucesso dos títulos, uma vez que os usuários estão cada vez mais desinteressados pelo típico modelo de reprodução de áudio que foi utilizado praticamente desde sua origem, o looping. Nesse sentido, o áudio dinâmico apresenta desafios ao designer de hipermídia, tendo em vista que a variabilidade de elementos sonoros é premissa de projeto, dadas as características de imprevisibilidade de ação do usuário.

O conceito de som interativo como sendo um evento disparado pelo usuário sugere que o mesmo é repetível e, se a ação for executada novamente, o disparo será acionado novamente. Nesse sentido, Collins (2013) pontua que essa repetição de eventos é um dos elementos-chave na capacidade do som em fornecer feedback aos usuários. A repetição estabelece uma expectativa: o usuário irá ouvir o mesmo som como uma confirmação de uma ação já anteriormente executada. Este feedback auxilia os usuários na medida em que a confirmação das suas ações aumenta a sua eficiência na execução de determinada tarefa. No entanto, a repetição possui uma desvantagem: os usuários podem passar a sentir-se incomodados com a o mesmo disparo sonoro por consecutivas vezes. A repetição de uma pista sonora pode afetar a imersão, como aponta Morton (2005) ao enfatizar que a prática exaustiva do looping é tida como uma maneira ineficaz de utilizar a música nos games:

\section{"Você não somente eliminou a eficácia emocional} da música, não a aplicando num contexto específico e generalizando-a, mas com a prática do looping exaustiva, você completamente separou o jogador da narrativa. E o que é pior, o loop geralmente se torna chato depois de um tempo" (MORTON, 2005; tradução livre).

Serafin (2004) aponta que loops e repetições na paisagem sonora são susceptíveis de serem detectados pelos usuários e percebidos como irreais, e Cancellaro (2006) pontua que sua utilização demasiada deve ser evitada. Caso os sons não sejam suficientemente relevantes no contexto da interface, estes podem tornar-se repetitivos e entediantes, gerando fadiga no ouvinte. O conceito de "fadiga do ouvinte" deve ser tratado com cautela: algumas interfaces são projetadas para uso consecutivo, e sons repetitivos podem ser cansativos, especialmente se o usuário passa muito tempo em uma área específica da interface. No caso dos games, em que a maioria dos títulos são projetados para serem jogados várias vezes, a audição repetida de um som pode tornar-se exaustiva. Para solucionar tal dificuldade, alguns games passaram a incorporar timings ${ }^{16}$ para as pistas de áudio, de modo que, se o usuário permanecer em determinado ambiente, a música não se repetirá infinitamente, mas em vez disso, simplesmente não mais será tocada. Collins (2008) argumenta sobre o game Halo, em que há um comando chamado "estou entediado". Se o usuário permanece no mesmo ambiente durante cinco minutos, a música de fundo desaparece, em fade.

Em ambientes interativos, a repetição incessante de um determinado som compromete a imersão, e isto é particularmente grave quando se utiliza o diálogo. Para os seres humanos, a voz humana é o som mais importante que existe. Desde bebês, os indivíduos aprendem a ouvir a voz humana, sendo possível absorver sutis nuances de frequência, volume e timbre que são capazes de alterar o sentido de uma sentença, como por exemplo, de um elogio para uma crítica. Segundo Stevens \& Raybould (2011), isto ocorre porque a audição é mais sensível no intervalo de frequências da qual a fala humana se propaga. Logo, é importante ter cautela com o uso excessivo de vozes humanas nas interfaces.

Um importante fator a ser considerado ao utilizar o discurso verbal nas interfaces diz respeito à própria natureza dos sistemas interativos. Estes ambientes permitem ao usuário retomar interfaces já anteriormente percorridas em seu trajeto de navegação. Mesmo que o usuário se depare com a repetição de elementos visuais e estruturais da interface, ao receber repetidamente estímulos auditivos pelos quais já foi exposto, o usuário pode absorver esta mesma informação como um "diálogo mecanizado", e suspender seu estado de imersão. Nesse contexto, sons verbais não devem ser disparados repetidamente em sistemas interativos. Dependendo da importância e relevância de seu conteúdo, os disparos sonoros verbais podem ser suprimidos no retorno do usuário à interface, permitindo-lhe ouvi-los novamente somente se desejar. Num cenário ideal, distintas capturas de um mesmo conteúdo devem ser realizadas contemplando distinções de timbre, tessitura,

\footnotetext{
${ }^{16}$ Períodos determinados de tempo; temporizadores.
} 


\section{Ergodesign \& HCI}

dinâmica vocal, de modo que o usuário possa se relacionar com os conteúdos sonoros de origem verbal de maneira menos repetitiva e mais humanizada.

A quantidade de informação que pode ser adicionada a uma interface através do som ainda é desconhecida. Serafin (2004) sugere que os objetos que são vistos e suscetíveis de emitir algum tipo de som devem ser sonorizados, porém sons de outros objetos em movimento que não são vistos pelo usuário podem distraí-lo. A autora exemplifica com base em um projeto no qual um jardim botânico fora recriado virtualmente. Neste, o som de pássaros havia sido artificialmente posicionado no topo da cabeça dos usuários, o que acabou por gerar certo grau de confusão, tendo em vista que os usuários procuravam pelas aves na interface, que não estavam presentes no ambiente virtual.

A duração de determinado estado de interface é um elemento complexo de se quantificar, tendo em vista que cada usuário a manipula de acordo com seu interesse. Logo, a experiência do usuário é fator determinante para que haja interatividade com os elementos sonoros presentes na interface. Para que o design de som venha a se integrar, de fato, ao design de interface, a solução mais apropriada é oferecer aos usuários o total controle sobre as possibilidades de som, tornando a abordagem do áudio dinâmico consonante com os princípios do design para a experiência do usuário.

\section{Considerações Finais}

Os ambientes interativos oferecem um campo novo e bastante singular de estudo que requer uma revisão de antigas teorias para que uma coerente abordagem entre design de som e design de interface possa ser realizada. No entanto, os ambientes interativos são muito distintos das formas tradicionais de mídia e, em muitos casos, a utilização de teorias advindas de outros campos pode não corresponder à completude de possibilidades e características que se aplicam no domínio da interface. Nesse contexto, as aplicações do som em plataformas interativas diferem-se das utilizadas nas mídias lineares tradicionais, como ocorre com a música, e o cinema.

Possibilidades significativas de melhorias no campo do design de som são dadas quando o som é analisado sob uma ótica abrangente no que diz respeito às suas características de conteúdo, forma e função. Em termos de percepção, tais parâmetros sonoros são difíceis de estimar com alta precisão, tornando-se ainda mais complexos quando no domínio da interface, que dão origem a uma equivalente perceptual que somente corresponde a uma realidade factual física aproximada, tendo em vista que muitos sons presentes nos dispositivos de IHC não possuem uma correspondente física, pois foram criados exclusivamente para utilização no dipositivo. A questão central, portanto, deve concentrar-se em apontar como os ouvintes processam os eventos acústicos da interface quando estes são tidos como processos de comunicação e, portanto, portadores de informações específicas.

Já existem conhecimentos científicos e tecnológicos suficientes para que seja possível iniciar um pensar sobre o som como uma das principais dimensões dos ambientes em que habitamos - sejam estes físicos ou virtuais. Isso significa superar a presença do som como ruído ${ }^{17}$ e promover uma atitude orientada ao canal auditivo como portador de informação, apropriando-se dos estímulos sonoros para transmitir mensagens sistematicamente.

\section{Referências Bibliográficas}

ALVES, Valter; ROQUE, Licínio. Guidelines for Sound Design in Computer Games. In: Grimshaw, M. (Ed.), Game sound technology and player interaction: Concepts and developments. Hershey, PA: IGI Global, 2011.

BAR-B-Q, Project. Group Report: Providing a High Level of Mixing Aesthetics in Interactive Audio and Games. The Thirteenth Annual Interactive Music Conference PROJECT BAR-B-Q 2008, San Antonio, USA, dec. 2008. Disponível em: $<$ http://www.projectbarbq.com/bbq08/bbq08r8.htm >. Acesso em: 15 jun. 2014.

BAR-B-Q, Project. Group Report: What is Interactive Audio? And What Should It Be? The Eighth Annual Interactive Music Conference PROJECT BAR-B-Q 2003, San Antonio, USA, section 5, dez., 2003. Disponível em:

\footnotetext{
${ }^{17}$ De acordo com Keeffe (2011), o temo ruído é frequentemente usado para descrever sons indesejáveis ou que possuem características que o definem como negativo e desagradável ao ouvinte.
} 
$<\underline{\text { http://www.projectbarbq.com/bbq03/bbq03r5.htm }}$

>. Acesso em: 15 jun. 2014.

BARTHES, R. Análise estrutural da narrativa: pesquisas semiológicas. Tradução de Maria Zélia Cardoso Pinto. $4^{\mathrm{a}}$ Ed. Petrópolis: Vozes, 1976.

BISHOP, M. J.; CATES, Ward Mitchell. Theoretical foundations for sound's use in multimedia instruction to enhance learning. Educational Technology Research and Development. Volume 49, Number 3, pp. 5-22, 2001.

BREWSTER, Stephen Anthony. Providing a Structured Method for Integrating Non-Speech Audio into Human-Computer Interfaces.

Submitted for the degree of Doctor of Philosophy. University of York, Human-Computer Interaction Group, Department of Computer Science. August, 1994.

CANCELLARO, Joseph. Exploring Sound Design for Interactive Media. Delmar Cengage Learning; 1 ed., 2006. Clifton Park, NY.

CARVALHO, Luiz Roberto; PEREIRA, Alice Theresinha Cybis. O Som Dinâmico em Interfaces Hipermídia: Áudio Interativo Direto e Áudio Adaptativo Indireto. In: IDEMi Integração para a Inovação - Artigos Selecionados: II Conferência Internacional de Integração do Design, Engenharia e Gestão para Inovação. Albertina Medeiros; Marcelo Gitirana. (Org.). 01ed.

Florianópolis: Fundação Universidade do Estado de Santa Catarina, v. 01, p. 246-261, 2012.

COLLINS, Karen. Game Sound: an introduction to the history, theory, and practice of video game music and sound design. Massachusetts, USA: MIT Press, 2008.

COLLINS, Karen. Playing with Sound: A Theory of Interacting with Sound and Music in Video Games. The MIT Press. January, 2013.

COLLINS, Karen; KAPRALOS, Bill. Sound Design for Media: Introducing Students to Sound. Journal of Sonic Studies, volume 6, nr. 1. Jan., 2014.

CORBETT, Richard; VAN DEN DOEL, Kees;
LLOYD, John E.; HEIDRICH, Wolfgang.

TimbreFields: 3D Interactive Sound Models for Real-Time Audio. Presence: Teleoperators \& Virtual Environments. Massachussets, USA: MIT Press Journals, v. 16, Issue 6, p. 643-654, dez., 2007.

DESMET, P. M. A.; HEKKERT, P. Framework of product experience. International Journal of Design, v. 1, n.1, 57-66, 2007.

ERMI, Laura; Frans Mäyrä (2005). Fundamental Components of the Gameplay Experience:

Analysing Immersion. Paper presented at the Digital Games Research Association Conference.

FOLLETT, Jonathan. Audio and the user experience. Disponível em:

http://www.uxmatters.com/mt/archives/2007/06/audi o-and-the-user-experience.php June 18, 2007.

Acesso em 17 set. 2015.

GAVER, W. Auditory Icons: Using sound in computer interfaces. Human Computer Interaction, 2(2), pp. 167-177, 1986.

GAVER, W. Synthesizing auditory icons. In S. Ashlund, K. Mullet, A. Henderson, E. Hollnagel, \& T. White (Ed.), INTERCHI'93, Amsterdam: ACM Press, Addison-Wesley, pp. 228-235, 1993.

GAVER, W. The SonicFinder: An interface that uses auditory icons. Human Computer Interaction, 4(1), pp. 67-94, 1989.

GAVER, W. Using and creating auditory icons. In G. Kramer (Ed.), Auditory Display, sonification, audification and auditory interfaces. The

Proceedings of the First International Conference on Auditory Display, Santa Fé Institute, Santa Fé: Addison-Wesley, pp. 417-446, 1992.

GAVER, William W. What in the World Do We Hear? An Ecological Approach to Auditory Event Perception. Ecological Psychology 5/1: 1-29, 1993b.

GRAU, Oliver (2003). Virtual Art: From Illusion to Immersion. Cambridge, Mass.: MIT Press.

IASIG; Interactive Audio Special Interest Group. Functions of Game Audio. [s;1], 2012. Disponível 
em:

$<$ http://www.iasig.org/wiki/index.php?title=Introduc tion>. Acesso em 12 jun. 2014.

ISO 9241. NBR 9241-11: Requisitos Ergonômicos para Trabalho de Escritórios com Computadores. Parte 11 - Orientações sobre Usabilidade. ABNT - Associação Brasileira de Normas Técnicas. Ago, 2011.

IUPPA, Nicholas; BORST, Terry. End-to-end game development: creating independent serious games and simulations from start to finish. Massachusetts, USA: Elsevier, 2010.

JEKOSCH, Ute. Sound Perception and Sound Design. 2nd ISCA/DEGA Tutorial \& Research Workshop on Perceptual Quality of Systems. Berlin, Deutschland, set., 2006.

JENNETT, C., COX, A. L., CAIRNS, P., DHOPAREE, S., EPPS, A., \& TIJS, T. Measuring and defining the experience of immersion in games. International Journal of Human-Computer Studies, 66, 641-661, 2008.

JØRGENSEN, K. Time for new terminology? Diegetic and non-diegetic sounds in computer games revisited . In: Grimshaw, M. (Ed.), Game sound technology and player interaction: Concepts and developments. Hershey, PA: IGI Global, 2011.

KAUSHANSKY, Karen. Designing With Audio: What Is Sound Good For? Diponível em: http://www.smashingmagazine.com/2012/04/designi ng-with-audio-what-is-sound-good-for/ April 18th, 2012. Acesso em 17 set. 2015.

KEEFFE, Linda O'. Sound is Not a Simulation: Methodologies for Examining the Experience of Soundscapes. In: Grimshaw, M. (Ed.), Game sound technology and player interaction: Concepts and developments. Hershey, PA: IGI Global, 2011.

LILJEDAHL, Mats. Sound for Fantasy and Freedom. In: Grimshaw, M. (Ed.), Game sound technology and player interaction: Concepts and developments. Hershey, PA: IGI Global, 2011.

MEARS, Chris. The UX of sound - designing audio experience. Disponível em: http://theuxreview.co.uk/ux-sound-designing-audioexperience/. Jan, 2014. Acesso em 17 set. 2015.

MENEGUETTE, L. C. Dead Space: estudo de caso e reflexões sobre áudio dinâmico. In: IV Gamepad Seminário de games, comunicação e tecnologia, 2011, Novo Hamburgo, RS: Universidade Feevale, 2011.

MORTON, Scott B. Enhancing the Impact of Music in Drama-Oriented Games. Gamasutra, 24 jan. 2005. Disponivel em:

http://www.gamasutra.com/view/feature/130602/enh ancing the impact of music in .php Acesso em 29 ago. 2016.

MOSES, Laura. Sound Design. EventDV. Vol. 23, Issue 1, p37, Jan/Feb2010.

MURCH, Walter. Dense Clarity - Clear Density. The transom review, Part 2, Vol. 5/Issue 1, April 1st, 2005. Disponível em:

http://transom.org/?page id=7006. Acesso em: 05 set. 2014.

MURRAY, J. H. Hamlet no holodeck: o futuro da narrativa no ciberespaço. São Paulo: Itaú Cultural: Unesp, 2003.

NORMAN, Donald A. O Design do dia-a-dia. Rio de Janeiro: Rocco, 2006.

PARKER, J. R; HEEREMA, John. Audio Interaction in Computer Mediated Games. International Journal of Computer Games Technology. vol. 2008, Article ID 178923, 8 pages. Hindawi Publishing Corporation, 2008.

PREECE, Jennifer. Design da Interação. Porto Alegre: Bookman. 2005.

ROCCHESSO, Davide et al. Sonic Interaction Design: Sound, Information and Experience. Conference on Human Factors in Computing Systems: CHI ' 08 extended abstracts on Human factors in computing systems. ACM Association for Computing Machinery, New York, NY, USA, 2008.

SALEN, Katie; ZIMMERMAN, Eric (2003). Rules of Play: Game Design Fundamentals. Cambridge, 
Mass.: MIT Press.

SERAFIN, Stefania. Sound Design to Enhance Presence in Photorealistic Virtual Reality. Proceedings of the 2004 International Conference on Auditory Display. Sidney, Australia, July 6-9, 2004.

STEVENS, Richard; RAYBOULD, Dave. The Game Audio Tutorial: A Practical Guide to Sound and Music for Interactive Games. Elsevier Inc. 2011.

STUART, R. Design of Virtual Environments. New York: McGraw-Hill. 1996.

SUSINI, Patrick; et al. Closing the Loop of Sound Evaluation and Design. 2nd ISCA/DEGA Tutorial \& Research Workshop on Perceptual Quality of Systems, Berlin; Deutschland, set., 2006.

TONG, Kam-pang Maya; WONG, Kam-wah. Schematic interface of sound creation for computer animators. Journal of Zhejiang University. China, Science A. vol. 7, n. 7, 2006.

TRACTINSKY, N.; ADI, S.-K.; IKAR, D. What is Beautiful is Usable. Interacting with Computers, 13, 127-145, 2000. 